\title{
Ultrasonic Guided Wave Signal Based Nondestructive Testing of a Bonded Composite Structure Using Piezoelectric Transducers
}

\author{
Kaleeswaran Balasubramaniam ${ }^{1}\left(\mathbb{D}\right.$, Shirsendu Sikdar ${ }^{2, *(D)}$, Piotr Fiborek $^{1}\left(\mathbb{D}\right.$ and Pawel H. Malinowski $^{1}(\mathbb{D}$ \\ 1 Institute of Fluid Flow Machinery, Polish Academy of Sciences, Department of Mechanics of Intelligent \\ Structures, Fiszera 14 Street, 80-231 Gdansk, Poland; kaleeswaranb@imp.gda.pl (K.B.); \\ pfiborek@imp.gda.pl (P.F.); pmalinowski@imp.gda.pl (P.H.M.) \\ 2 Mechanics of Materials and Structures, Department of Materials, Textiles and Chemical Engineering, \\ Ghent University, Technologiepark-Zwijnaarde, 469052 Ghent, Belgium \\ * Correspondence: Shirsendu.Sikdar@UGent.be
}

check for updates

Citation: Balasubramaniam, K.; Sikdar, S.; Fiborek, P.; Malinowski, P.H. Ultrasonic Guided Wave Signal Based Nondestructive Testing of a Bonded Composite Structure Using Piezoelectric Transducers. Signals 2021, 2, 13-24.

https://doi.org/10.3390/ signals2010002

Received: 24 August 2020 Accepted: 22 December 2020 Published: 15 January 2021

Publisher's Note: MDPI stays neutral with regard to jurisdictional clai$\mathrm{ms}$ in published maps and institutional affiliations.

Copyright: (C) 2021 by the authors. Licensee MDPI, Basel, Switzerland. This article is an open access article distributed under the terms and conditions of the Creative Commons Attribution (CC BY) license (https:// creativecommons.org/licenses/by/ $4.0 /)$.

\begin{abstract}
This paper presents ultrasonic guided wave (UGW) propagation-based nondestructive testing (NDT) of an adhesively bonded composite structure (ACS). In the process, a series of scanning laser Doppler vibrometry (SLDV)-based laboratory experiments and time-domain spectral element method (SEM)-based numerical simulations were carried out on an ACS with barely visible impact damage (BVID) and a hole. A good agreement was observed between the numerical and experimental UGW signals in the cases studied. Finally, a full-field and elliptical signal processing method-based NDT strategy was proposed that uses differential damage features of the registered UGW signals to identify different types of BVIDs in the ACS.
\end{abstract}

Keywords: ultrasonic guided signal; adhesively bonded composite structure; barely visible impact damage; laser-vibrometry; damage detection

\section{Introduction}

Aluminum Nomex sandwich core structure materials are mainly used in the automobile and aerospace industry due to their high strength-to-weight ratio. Evaluation of these materials is periodically necessary to prevent the impact of disasters on their entire structures. Barely visible impact damage (BVID) is a type of damage that occurs due to drop impacts or mishandling of tools, leading to small or large indentations in the materials. These have a lesser impact on aluminum or steel, but on fiber-reinforced polymers, such as in glass fiber reinforced polymer (GFRP) or honeycomb structures, can cause changes due to core/core crushing or failure of the matrix. Scanning laser Doppler vibrometry (SLDV) is an advanced nondestructive testing (NDT) tool used in the industry to detect the early stage of damage. SLDV is reliable, handles large materials, and detects damage-sensitive regions. An ultrasonic guided wave (UGW) helps to evaluate such defects because they can propagate long distances, and its excitation is achieved by a piezo zirconium titanate (PZT) actuator. These Lamb waves are reflected from discontinuities and thus help to provide a clear visualization of the damaged region. The usage of UGWs in multi-layered structures is well known and has been presented by many authors [1,2]. UGWs occur in the form of asymmetric and symmetric waves [1]. When the UGW interacts with the damaged region, it is reflected, mode conversion takes place, and interference in the wave field occurs [2]. Thus, with the help of SLDV and signal processing methods, the analysis of scattered waves is explored. SLDV works on the principle of the Doppler effect and observation of the Doppler shift in frequency. SLDV uses either Nd: YAG or Helium-Neon (He-Ne) lasers. SLDV is mainly applied to detecting BVID [3] and delamination [4], and in debonding analysis [5]. The paper [6] refers to experimental studies of identifying debonding and delamination using SLDV in honeycomb structures. The A0 waves of the guided waves have both leaky and non-leaky characteristics and could reliably detect 
debonding [7]. Other research refers to SLDV studies on aluminum honeycomb sandwich structures [8]. The impact test on the 3D composite honeycomb structure was studied with the use of SLDV and numerical methods [9]. The magnitude of the wave depends on the core of the honeycomb structures [10]. The evaluation of BVIDs in sandwich honeycomb plate using PZT excited guided waves [11] was presented using time-reversal methods. Analysis of honeycomb structures with debonding at varying temperature conditions was undertaken using guided waves, and identification of damage using damage index maps was shown [12]. Numerical and experimental analysis [13] of debonding in composite structures was carried out using guide waves.

The spectral element method (SEM) developed for the numerical solution of the laminar fluid flow by Patera [14] combines the flexibility of the finite element method (FEM) and fast convergence of spectral methods in the frequency domain. This SEM technique was successfully implemented in the field of modelling the phenomena of elastic wave propagation [14-18]. In the current research paper, we used SLDV to analyze the BVID in a semi-sandwich panel with a Nomex core and aluminum skin. The damage caused by impacts of 4 and $10 \mathrm{~J}$ was studied. In one region, a small portion of Nomex core was completely removed manually to make an indentation and, in another region, an indentation with a Nomex core protrusion was studied. The results obtained from SLDV were compared with numerical studies to visualize the damage region. The numerical approach was performed using the spectral element method (SEM) code. The gathered data was processed with the elliptical signal processing method for damage localization with various sensor network arrangements.

The paper is structured as follows. The experimental and numerical process is explained in Section 2. Section 3 presents results obtained from the SLDV, SEM, and the elliptical-based code. The paper is concluded in the fourth section.

The novelties in this paper are as follows:

- A sandwich plate with Nomex core and single-sided adhesively bonded aluminum facet is studied experimentally, numerically, and analytically.

- SEM study with PZT SONOX P502 parameters is studied with a single-sided adhesively bonded composite structure (ACS).

- The SLDV full wavefield result is compared with the SEM result.

- The elliptical method is applied to the data obtained from SLDV and SEM.

- The elliptical signal method is not limited to the first time of arrival and does not use the differential signals.

\section{Numerical and Experimental Process}

The investigated ACS was made of an aluminum skin (face) and a Nomex honeycomb core. The BVID was made by low energy impacts (4 and $10 \mathrm{~J}$ ) from the Nomex core side. A BVID of diameter $1.4 \mathrm{~cm}$ (BVID 1) was made with an impactor by crushing the Nomex cells, and another BVID of diameter $1.8 \mathrm{~cm}$ (BVID 2) was also made with an impactor after removing the Nomex cells. The device used to create the BVID was a circular impactor of $10 \mathrm{~cm}$ diameter. The specimen is shown in Figure 1a. The largest diameter BVID 2 is magnified in Figure 1b, and Figure 1c shows the cross-section of the plate with the Nomex core and a one-sided aluminum facet. The Nomex core attached to the facet is shown in Figure $1 \mathrm{~d}$ with an area where the BVIDs were made. BVIDs of diameters $1.4 \mathrm{~cm}$ (BVID 1) and $1.8 \mathrm{~cm}$ (BVID 2), and a hole of $0.5 \mathrm{~cm}$ diameter, constitute the damage. The SLDV is an NDT device largely used in industry to analyze the vibrations of structures. The SLDV instrument used was a PSV 400 from Polytec (c) GmbH. Laser vibrometry uses the Doppler effect for non-contact optical vibration analysis. This uses light as a sensor and thus a contactless experimental process. This yields real-time measurements of temporal signatures and is based on the frequency of the laser shift between the reference beam and the incident beam from the laser. The interferometer inside the laser head analyzes this shift by propagating it to the photodetector. Thus, depending on the velocity, the backscattered light gets changed in frequency and phase. 


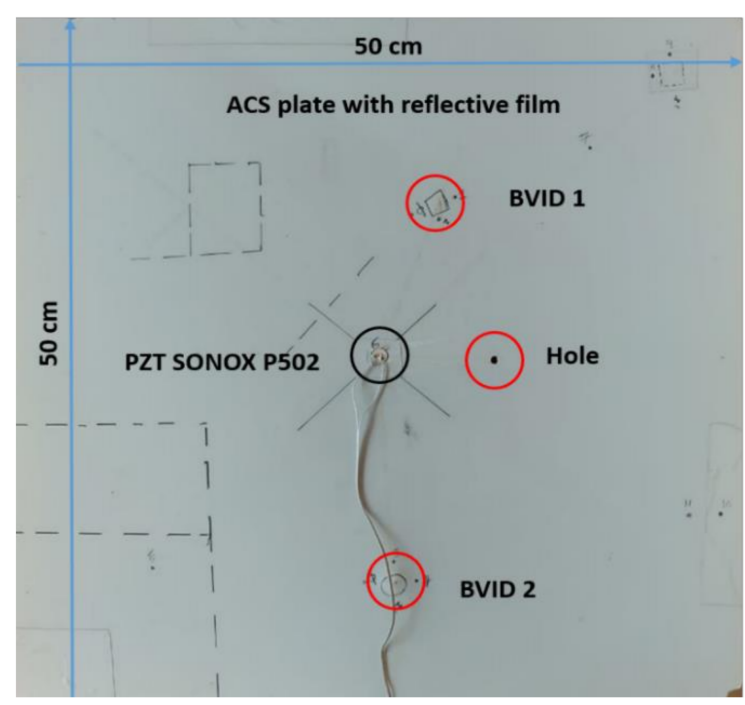

(a)

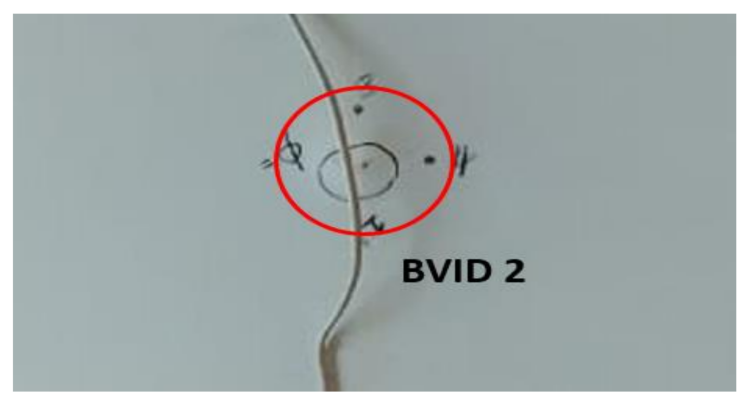

(b)
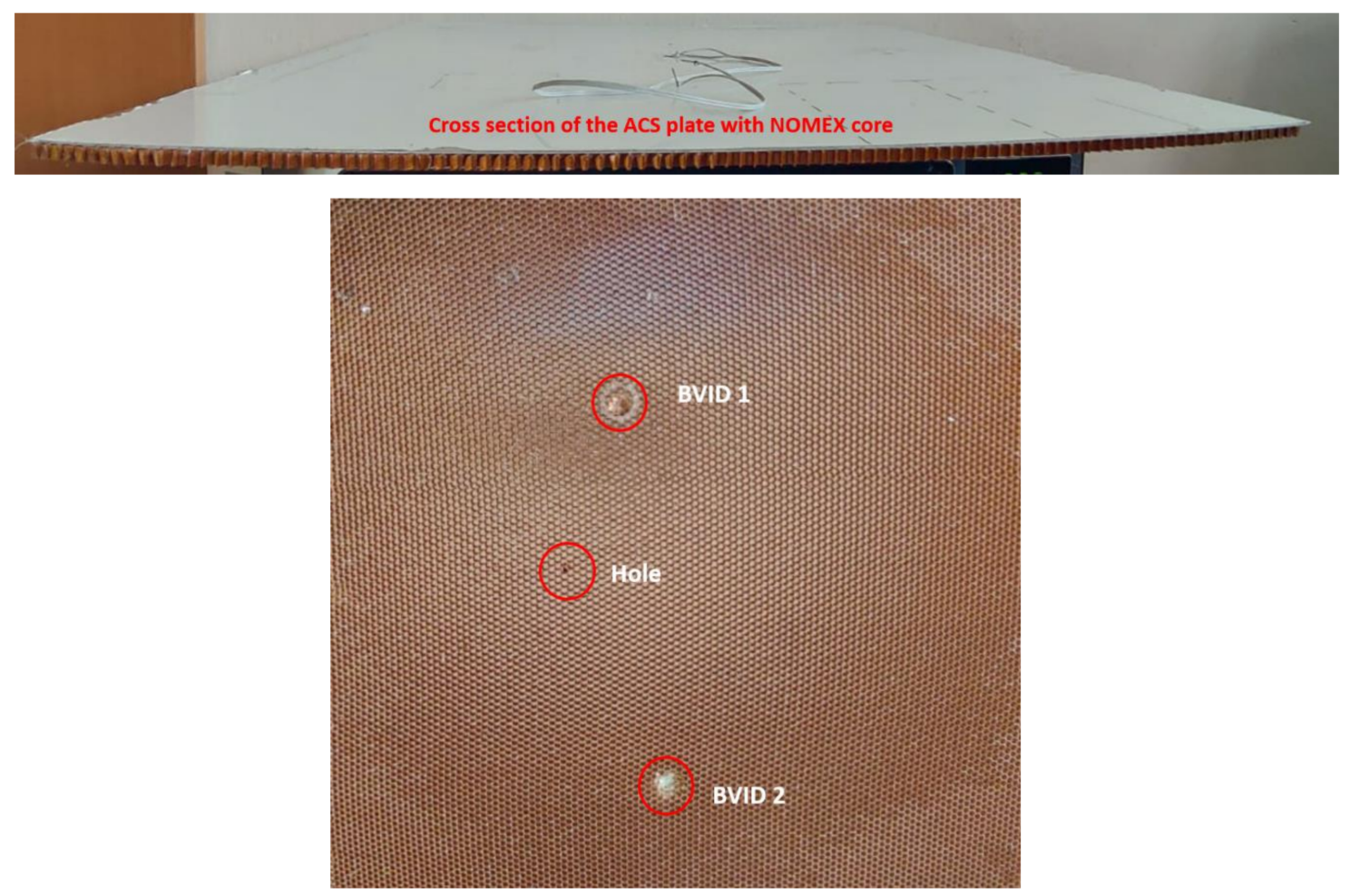

(d)

Figure 1. (a) ACS plate with damages; (b) zoomed image of BVID 2; (c) cross-section of the plate with the core; (d) Nomex core attached at the backside of the plate and region where a hole and BVIDs were made. 
Thus, the Doppler shift in frequency is analyzed based on the modulated detected output signals. Using inbuilt signal processing techniques, the velocity and displacement of the surface waves are detected. The PZT (SONOX P502) was bonded with a bonding glue to the plate. A sine tone burst signal with 10 cycles at $16 \mathrm{Vpp}$ amplified 20 times produced the excitation. The measurement parameters are summarized in Table 1. During the experiment, the room was maintained with a constant temperature of $21{ }^{\circ} \mathrm{C}$ using air conditioning.

Table 1. Experimental table with measurements performed in the scanning laser Doppler vibrometry (SLDV).

\begin{tabular}{ccccc}
\hline No. of Cycles & Frequency $\mathbf{( k H z )}$ & Excitation Voltage $(\mathbf{V p p})$ & Grid Points & Sampling Period $(\boldsymbol{\mu s})$ \\
\hline 10 & 150 & $16 \times 20$ & $411 \times 415$ & 0.78125 \\
\hline
\end{tabular}

For the spectral element method (SEM), only the hole of $\varnothing 0.5 \mathrm{~cm}$ was studied. The engineering constants used for the analysis are highlighted in Table 2 [19]. The parameters used in SEM are explained in Tables 3-5.

Table 2. Engineering constants of the ACS used in the numerical study.

\begin{tabular}{cccc}
\hline Material & Young's Modulus (GPa) & Poisson Ratio & Density $\left(\mathbf{k g} / \mathbf{m}^{\mathbf{3}}\right)$ \\
\hline Nomex & 9 & 0.30 & 1384 \\
Aluminum & 68 & 0.33 & 2600 \\
\hline
\end{tabular}

Dielectric, electromechanical, and mechanical properties used for the PZT (SONOXP502) are shown in Tables 3 and 4 , where: $\mathrm{d}_{33}, \mathrm{~d}_{31}, \mathrm{~d}_{15}$ are charge constants; $\frac{\varepsilon_{33}^{\mathrm{T}}}{\varepsilon_{0}}, \frac{\varepsilon_{11}^{\mathrm{T}}}{\varepsilon_{0}}$ are relative permittivity values; $S_{11} E, S_{33}{ }^{E}$ are elastic compliance values; $\rho$ represents the density value; $\eta_{13}$ represents the Poisson ratio. The manufacturer of the PZT provided all of the properties [20].

Table 3. Electromechanical and dielectric properties of the PZT actuator.

\begin{tabular}{ccccc}
\hline $\mathbf{d}_{33}(\mathbf{C} / \mathbf{N})$ & $\mathrm{d}_{\mathbf{3 1}}(\mathrm{C} / \mathbf{N})$ & $\mathrm{d}_{\mathbf{1 5}}(\mathbf{C} / \mathbf{N})$ & $\frac{\varepsilon_{33}^{\mathrm{T}}}{\varepsilon_{0}}$ & $\frac{\varepsilon_{11}^{\mathrm{T}}}{\varepsilon_{0}}$ \\
\hline $440 \times 10^{-12}$ & $-185 \times 10^{-12}$ & $560 \times 10^{-12}$ & 1850 & 1950 \\
\hline
\end{tabular}

Table 4. Mechanical properties of PZT and other values.

\begin{tabular}{cccc}
\hline $\mathrm{S}_{11}{ }^{\mathrm{E}}\left(\mathrm{m}^{\mathbf{2}} / \mathrm{N}\right)$ & $\mathrm{S}_{33} \mathrm{E}\left(\mathrm{m}^{2} / \mathrm{N}\right)$ & $\eta_{13}$ & $\rho\left(\mathrm{kg} / \mathrm{m}^{3}\right)$ \\
\hline $18.5 \times 10^{-12}$ & $20.7 \times 10^{-12}$ & 0.44 & 7740 \\
\hline
\end{tabular}

Table 5. Numerical spectral element method (SEM) table with values used.

\begin{tabular}{cccc}
\hline No. of Cycles & Frequency (kHz) & Grid Points & Sampling Period $(\boldsymbol{\mu s})$ \\
\hline 10 & 150 & $251 \times 251$ & $6.1 \times 10^{-3}$ \\
\hline
\end{tabular}

The SEM technique, similarly to FEM, divides the modelled domain into finite elements, imposing the arbitrary boundary conditions and external forces in the particular nodes. Distribution of the nodes in the element is the main difference between the two methods: the nodes in SEM are non-uniformly distributed and coincident with the coordinates of the Gauss-Lobatto-Legendre (GLL) integration points. The shape functions for two-dimensional (2D) spectral elements are obtained by the Kronecker product of one-dimensional (1D) shape functions, denoted by $\otimes$ as shown in Equation (1).

$$
\operatorname{Nmn}(\hat{\imath}, c ̧)=\operatorname{Nm}(\hat{\imath}) \otimes N n(c ̧), \text { for } m=1 \ldots p, n=1 \ldots r
$$


where $\mathrm{p}-1$ and $\mathrm{r}-1$ are the degrees of interpolating polynomial, and $i, c \in[-1,1]$ are element local coordinates. As a consequence of the orthogonality of shape functions, and the application of the GLL quadrature, the mass matrix is diagonal in the formulation. This property significantly reduces computation time for solving the equation of motion due to avoiding mass matrix inversion.

\section{Results and Discussion}

\subsection{Analysis of the Results from the SLDV}

Velocity plots obtained directly from the SLDV were analyzed. The Lamb wave propagation of the specimen is visualized in Figure 2. The schematic representation of the PZT placement and damage locations are shown in Figure 2a. The experiment was carried out with frequency ranges of 10, 15, 20, 25, 50, 100, 150, and $200 \mathrm{kHz}$, and it was found that the $150 \mathrm{kHz}$ frequency provides good visualization of results. The full wavefield results obtained from $150 \mathrm{kHz}$ at different time periods are analysed. Figure $2 \mathrm{~b}$ shows the propagation of the waves in the form of circles. The waves reach the damage region (hole) and are distracted, thus showing the location and damage shape. This perfectly shows the hole region with scattered Lamb waves. The amplitude of the S0 mode is much lower than A0 mode, therefore, it is barely noticeable in the full field of the wave measured by the SLDV. Thus, the antisymmetric A0 mode waves are predominantly visible and marked in all of the figures. When the waves reach the damage zone, they are reflected and mode change occurs. The important aspect is to visualize the wave reflections after they touch the impact damage zone. The SLDV helps in quality analysis of the material without destroying it. Figure $2 \mathrm{c}$ shows the detection of BVID 1 . The waves are scattered at the damage region (marked with black circles) and mode change occurs. Figure $2 \mathrm{~d}$ shows the wave pattern analysis and detection of BVID 2. As mentioned earlier, SLDV is a powerful NDT tool. In our previous research, we identified debonding with a diameter of $0.5 \mathrm{~cm}$ in honeycomb structures with $15 \mathrm{kHz}$ and $0.9 \mathrm{~cm}$ BVID in carbon fiber reinforced polymer (CFRP) structures with $150 \mathrm{kHz}$.

The SLDV measures the out-of-plane displacement and helps in the early inspection. As shown in Figure 2, one can visualize the $S$ waves reaching the damaged region and its conversion. This shows a clear visualization of the damage. The times required for the waves to reach the damage zones are summarized in Table 6.

Table 6. Times required for detection of damage.

\begin{tabular}{cccc}
\hline Frequency $(\mathbf{k H z})$ & Hole $(\boldsymbol{\mu s})$ & BVID 1 $(\boldsymbol{\mu s})$ & BVID 2 $(\boldsymbol{\mu s})$ \\
\hline 150 & 29 & 37 & 48 \\
\hline
\end{tabular}




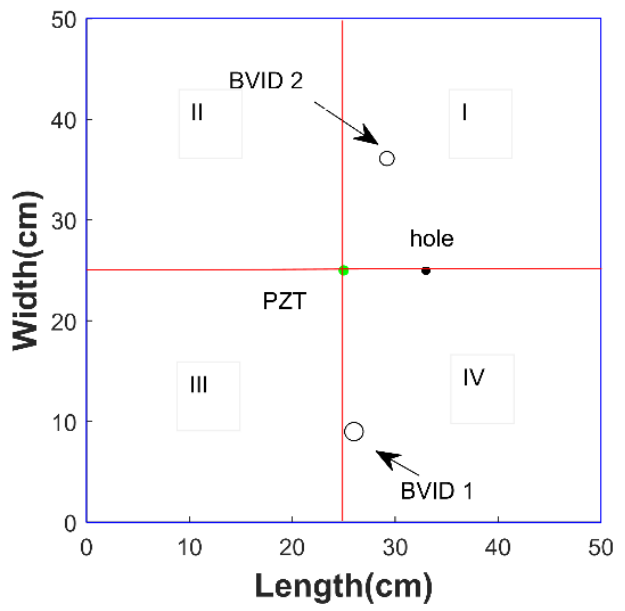

(a)

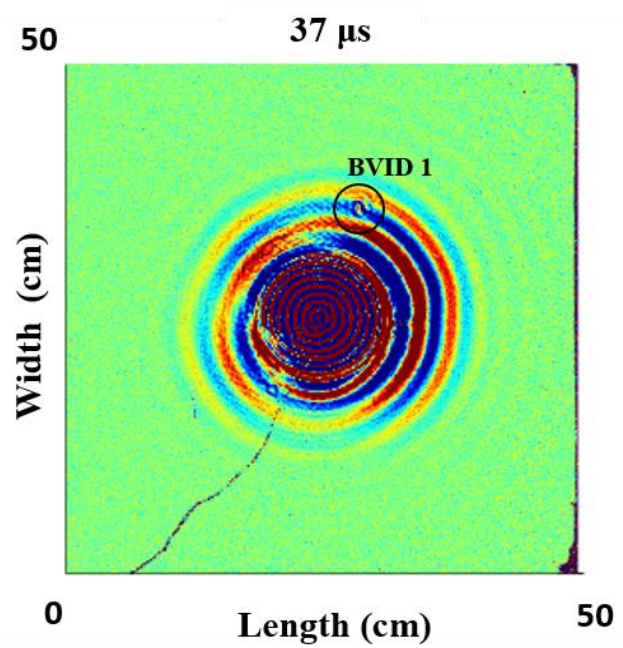

(c)

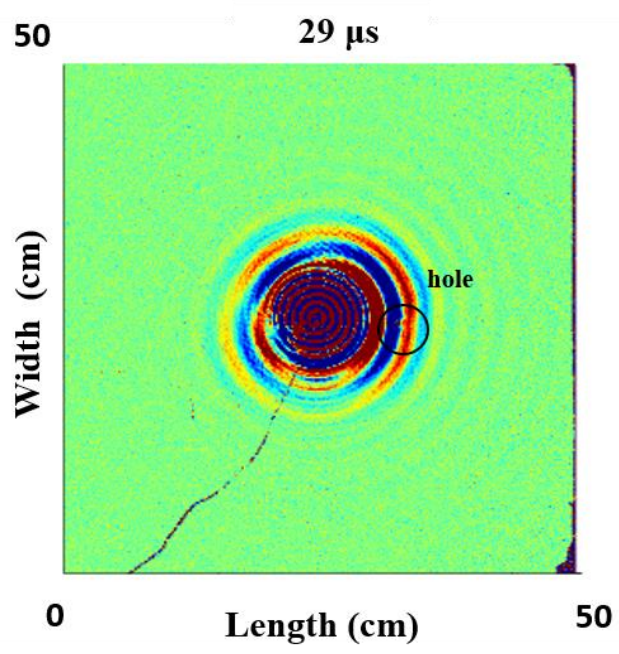

(b)

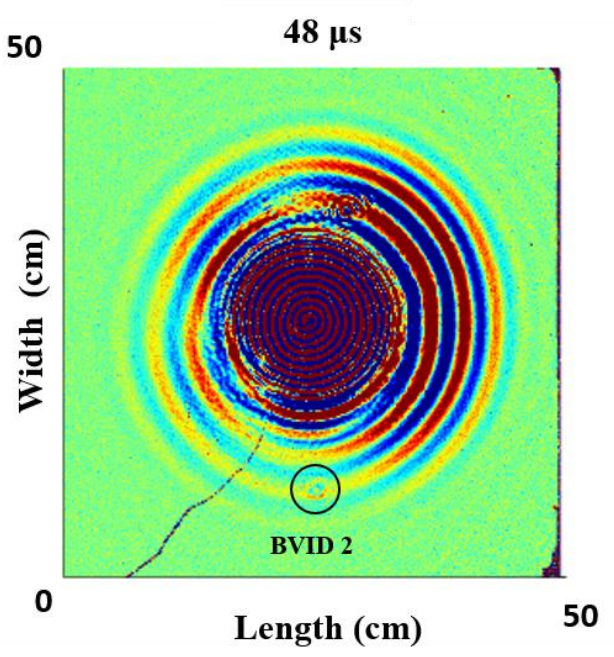

(d)

Figure 2. (a) Schematic representation of PZT, damage zones; (b) a hole of $\varnothing 0.5 \mathrm{~cm}$ detected at $29 \mu \mathrm{s} ;$ (c) BVID 1 detected at $37 \mu \mathrm{s} ;(\mathbf{d})$ BVID 2 detected at $48 \mu \mathrm{s}$.

\subsection{Analysis of the Results Using Numerically Based Spectral Element Code}

In this section, the numerical results from the SEM are shown. The main idea is to check the experimental results visualized with the numerical studies and to undertake a proper comparison of the results. For this spectral elemental study, a hole with $\varnothing 0.5 \mathrm{~cm}$ section was selected to be analyzed. Figure 3a shows the mesh arrangement and PZT position in the SEM approach, and Figure $3 b$ shows the result obtained with the SEM numerical study.

Thus, a comparative study of numerical analysis and experimental results shows that the hole was detected at a time of $29 \mu$ s in both cases, as shown in Figures $2 b$ and $3 b$, respectively. The comparison of the experimental and numerical results in Figures 2 and 3 reveals the wave field of the Lamb waves and its change due to the damage zones. 


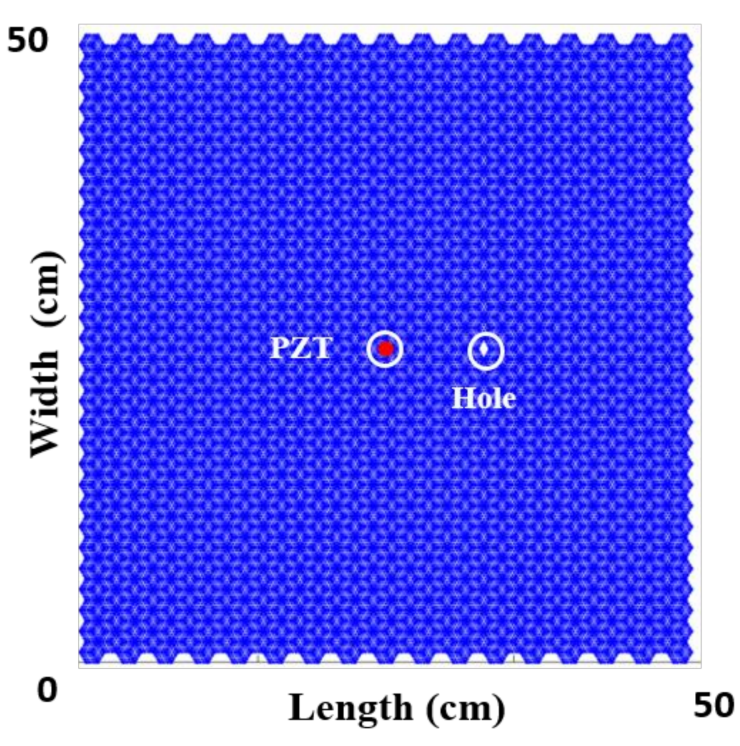

(a)

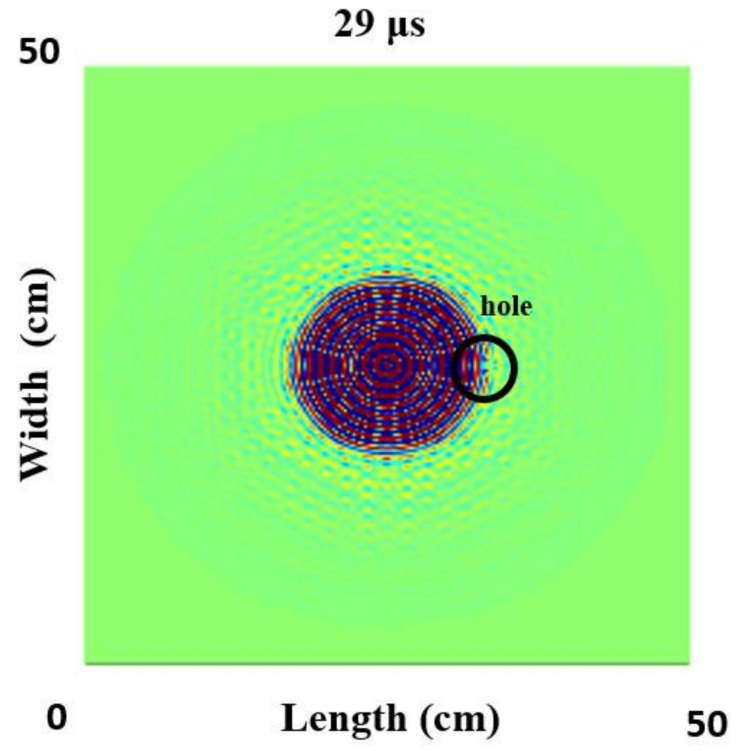

(b)

Figure 3. (a) Mesh arrangement and PZT position in SEM; (b) hole of $\varnothing 0.5 \mathrm{~cm}$ detected at $29 \mu \mathrm{s}$ for $150 \mathrm{kHz}$ excitation.

\subsection{Analysis of the Results Using an Elliptical Based Signal Processing Method}

This section focuses on the application of the elliptical-based signal processing method to localizing the damage [21]. The underlying concept is the intersection of the ellipses that correspond to wave reflections. The region where a large number of ellipses intersects identifies the damage location. Optimum sensor positioning for damage localization is considered. Six cases with different sensor positioning are shown in Table 7. The sensor placements for cases 1 and 5 were taken from research on the optimal sensor placement assisted with a genetic algorithm reported in [22]. In all of the cases, the scanning points were placed at a distance of $10 \mathrm{~cm}$.

Table 7. Case models for elliptical approach with experimental and numerical data.

\begin{tabular}{cccc}
\hline Case & Test & Sensor Placement & No. of Sensing Points \\
\hline 1 & Experimental & Quadrant I, II, III, IV & 8 \\
2 & Experimental & Quadrant I, II & 4 \\
3 & Experimental & Quadrant III, IV & 4 \\
4 & Experimental & Quadrant II & 6 \\
5 & Numerical & Quadrant I, II, III, IV & 8 \\
6 & Numerical & Quadrant II & 6 \\
\hline
\end{tabular}

For the elliptical-based method, a velocity profile was determined because the velocity can be angle-dependent. The steps performed to obtain the velocity profile are summarized with the equation:

$$
\text { Velocity }[\mathrm{m} / \mathrm{s}]=\frac{\text { delx }}{\text { delt }}
$$

where delx is the distance between the scanning points (grid points in the case of SLDV and nodal points in the case of SEM) and delt = TOA2 - TOA1, where TOA represents the wave time of arrival at a given scanning point. The calculation of delt between two points located at 0 degrees of the signals of cases 4 and 6 are shown in Figure 4. Figure 4 a shows experimental signals and Figure $4 \mathrm{~b}$ shows the numerical SEM signals. Table 8 shows the velocity values obtained for cases 4 and 6 . The velocity profile was calculated by taking these velocity values and fitting them to an elliptical function. This gives the entire $360^{\circ}$ plot (Figure 5). Because the 0 and $90^{\circ}$ values are similar, the fit results in an almost perfect 
circular profile. These velocity profiles were used for the elliptical-based method.

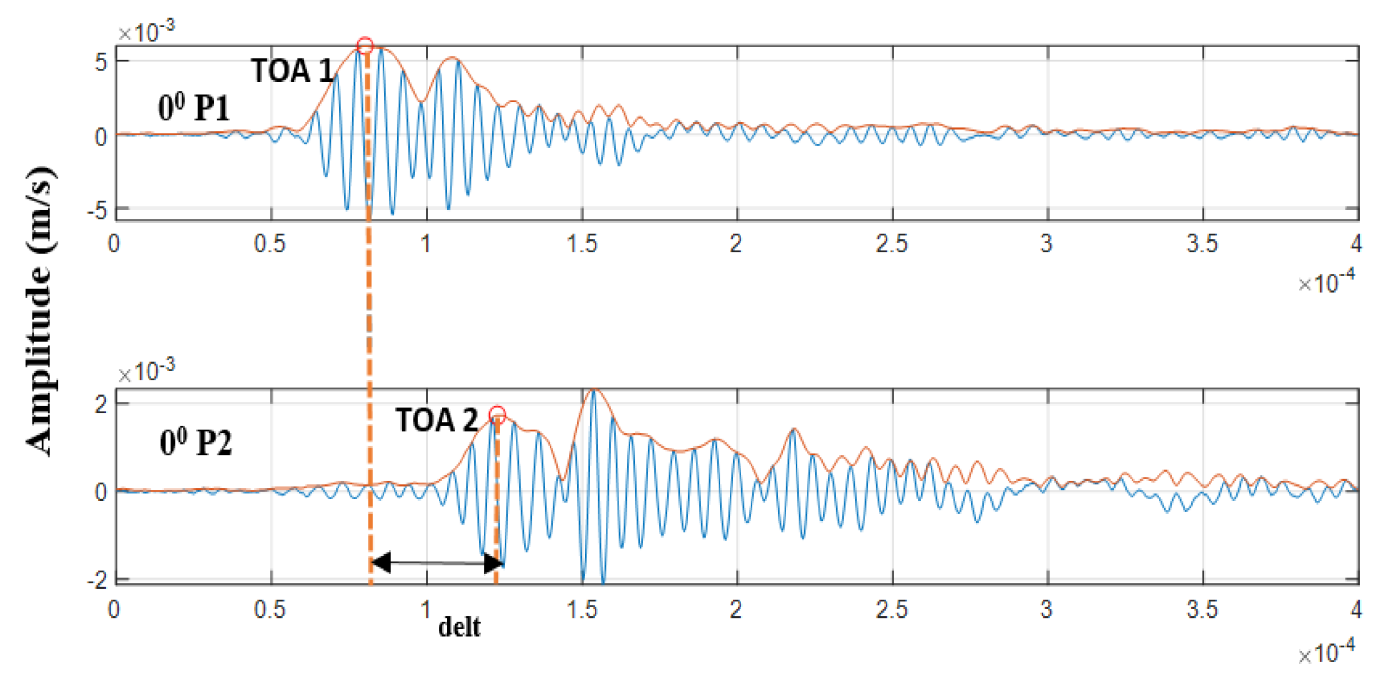

Figure 4. delt calculation between two points (a) SLDV measurement; (b) numerical SEM.

Table 8. Group velocities obtained from SLDV, SEM measurement.

\begin{tabular}{ccc}
\hline Cases Studied & Group Velocity $[\mathrm{m} / \mathbf{s}]$ at $\mathbf{0}^{\circ}$ & ${\text { Group Velocity }[\mathrm{m} / \mathbf{s}] \mathbf{~ a t ~}^{\mathbf{9 0}}}^{\circ}$ \\
\hline Case 4 & 2048 & 2108 \\
Case 6 & 2410 & 2365 \\
\hline
\end{tabular}

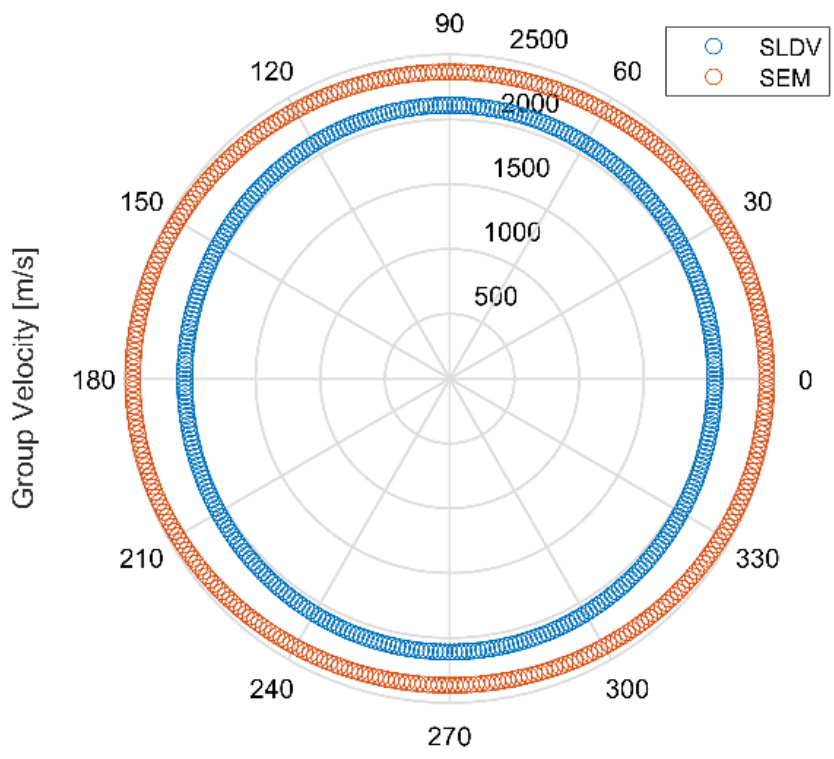

Degrees [o]

Figure 5. Velocity profile obtained.

Initially, the elliptical method was applied to the complete experimental case 1 with 2 BVIDs and a hole as shown in Figure 6a. The intersection of white dotted lines in all of the figures with the results indicates the region where the damage map maximum is identified. The result for case 1 shows that only the hole location was indicated, as seen in Figure 6b. Scanning points in quadrants I and II (case 2) identified the energy convergence zone near to BVID 1, as shown in Figure 6c. Scanning points in quadrants III and IV (case 3) identified the energy convergence zone near to BVID 2, as shown in Figure 6d. Different sensor 
arrangements in case 4 (quadrant II-Figure 6e) indicated the location of the hole (Figure 6f). Table 9 provides the error estimation of cases 1-4 with the experimental data.

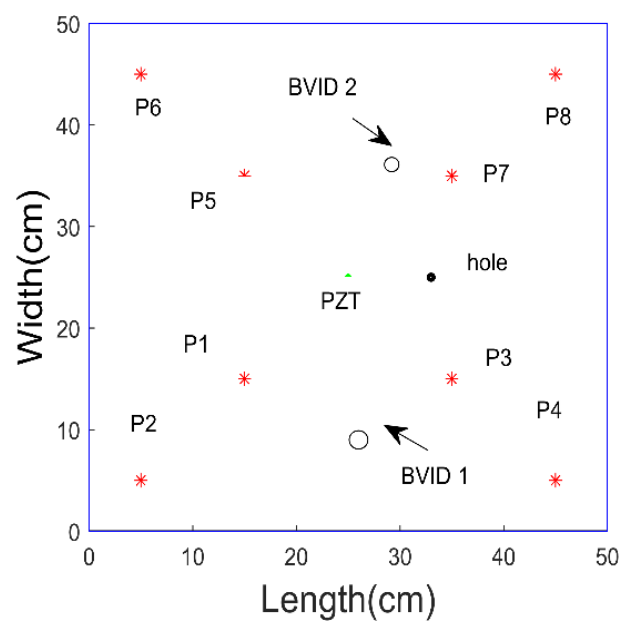

(a)

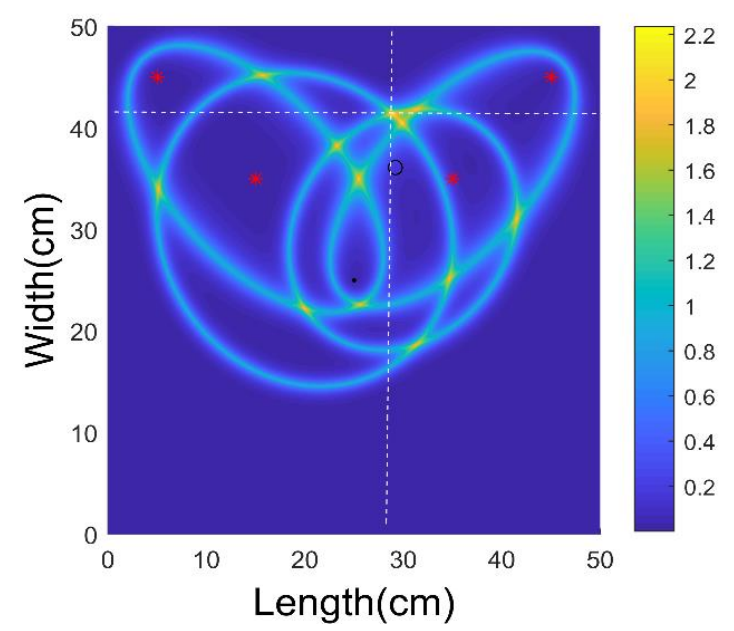

(c)

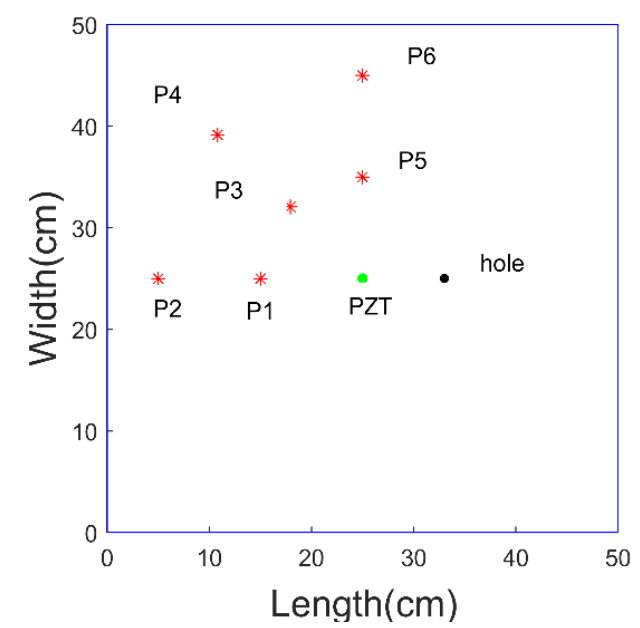

(e)

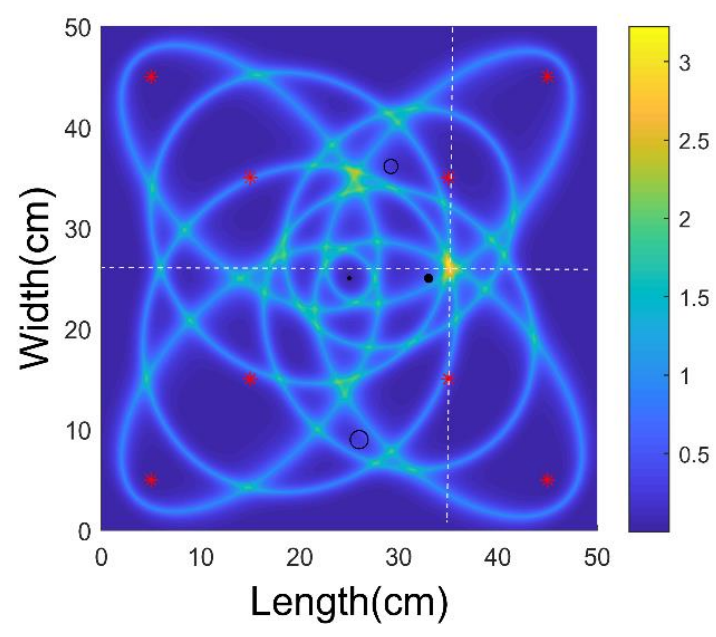

(b)

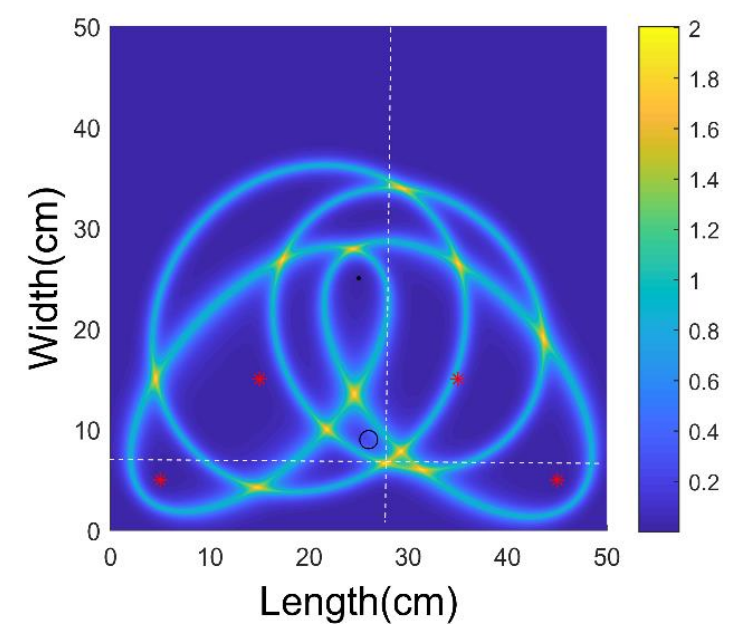

(d)

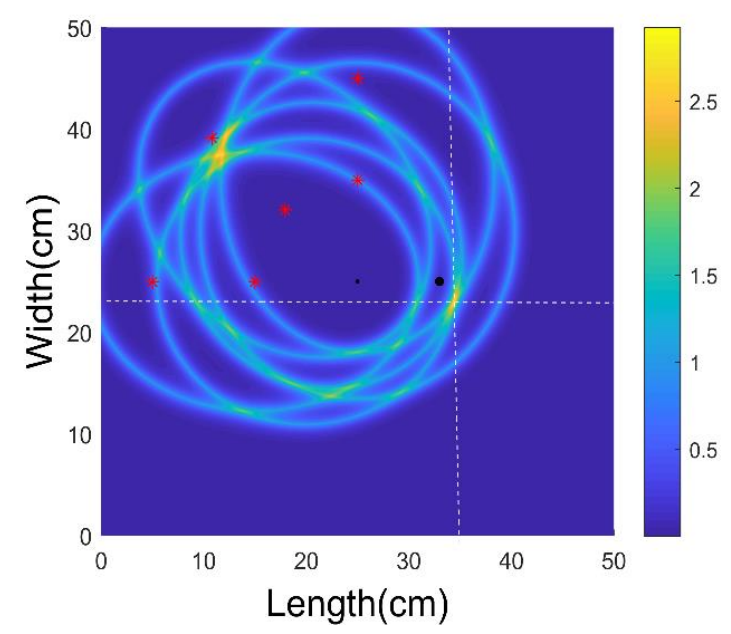

(f)

Figure 6. Experimental case: (a) case 1 quadrant I-IV arrangement of sensors; (b) elliptical method on case 1; (c) elliptical method on case 2; (d) elliptical method on case 3; (e) case 4 quadrant II arrangement of sensors; (f) elliptical method on case 4. 
Table 9. Error estimation of experimental cases.

\begin{tabular}{cccc}
\hline Experimental & $\begin{array}{c}\text { Damage Map Maximum } \\
\text { Location } \mathbf{( c m}, \mathbf{c m})\end{array}$ & $\begin{array}{c}\text { Coordinates of Damage } \\
\text { Center } \mathbf{( c m}, \mathbf{c m})\end{array}$ & $\begin{array}{c}\text { Error in Estimation } \\
\mathbf{( c m})\end{array}$ \\
\hline Case 1 & $(35,26.5)$ & $(33.0,25.0)$ & 2.50 \\
Case 2 & $(28.9,41.4)$ & $(29.1,36.2)$ & 5.20 \\
Case 3 & $(27.7,6.7)$ & $(26.0,9.0)$ & 2.80 \\
Case 4 & $(34.4,23.0)$ & $(33.0,25.0)$ & 2.44 \\
\hline
\end{tabular}

Research was also conducted on the data obtained from a numerical study (case 5 and 6), which was simpler due to only one form of damage, and yielded clear results as shown in Figure 7. Figure 7a shows the sensor network placement of case 5. Analysis of the results from Figure 7 shows the region of higher energy where ellipses are more coincident. Figure $7 \mathrm{~b}$ shows the convergence results obtained for case 5 . Figure $7 \mathrm{c}$ shows the sensor network placement of case 6 . In Figure $7 d$, the damage hole region is properly detected with the help of intersecting ellipses (case 6). The higher energy is due to wave reflection from the damage. This result is obtained by analyzing results from various peak values extracted from the time signals. The error estimation values obtained with the elliptical method for the numerical SEM cases (cases 5 and 6) are shown in Table 10.

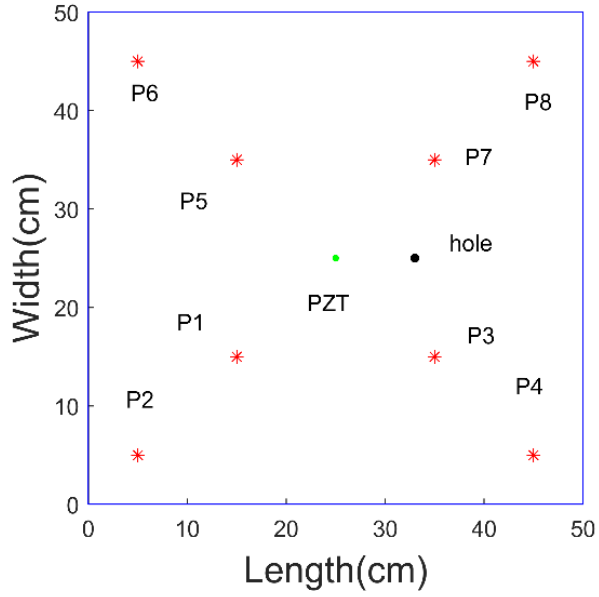

(a)

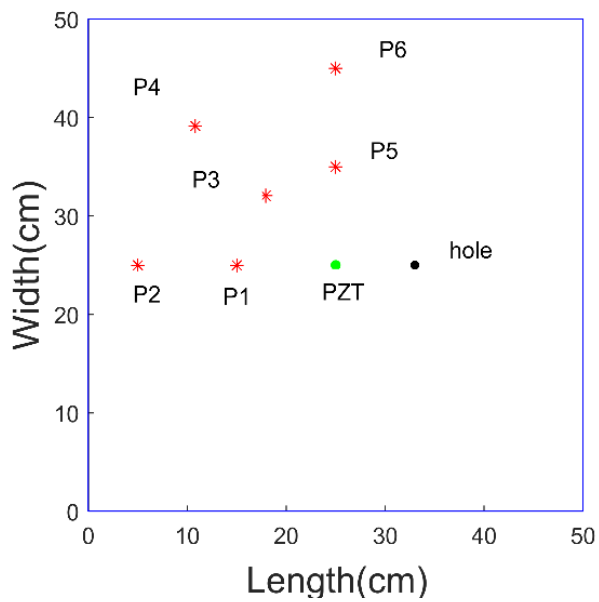

(c)

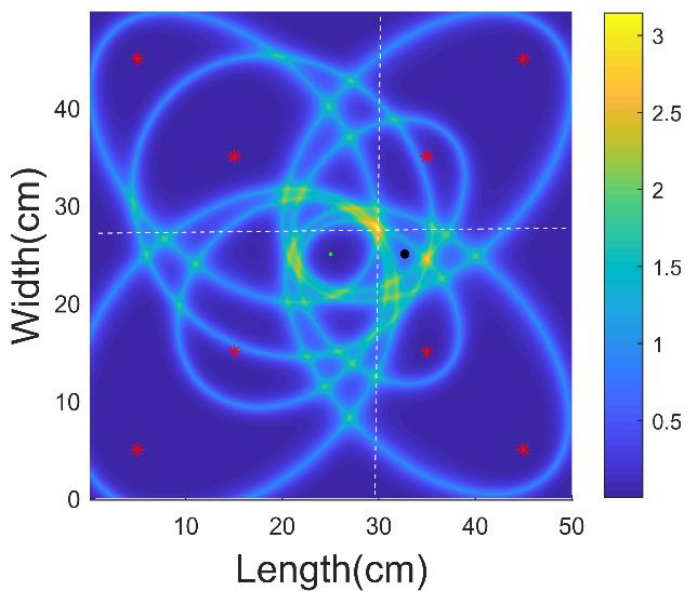

(b)

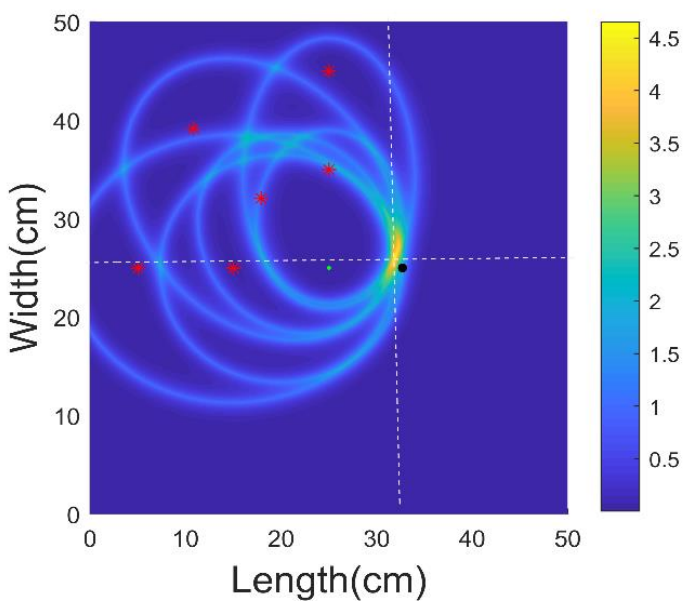

(d)

Figure 7. Numerical cases: (a) case 5 quadrant I-IV arrangement of sensors; (b) elliptical method on case 5; (c) case 6 quadrant II arrangement of sensors; (d) elliptical method on case 6. 
Table 10. Error estimation of numerical cases.

\begin{tabular}{cccc}
\hline Numerical & $\begin{array}{c}\text { Damage Map } \\
\text { Maximum Location } \\
(\mathbf{c m}, \mathbf{c m})\end{array}$ & $\begin{array}{c}\text { Coordinates of } \\
\text { Damage Center } \mathbf{( c m}, \\
\mathbf{c m})\end{array}$ & $\begin{array}{c}\text { Error in Estimation } \\
\mathbf{( c m )}\end{array}$ \\
\hline Case 5 & $(29.8,27.7)$ & $(33.0,25.0)$ & 4.10 \\
Case 6 & $(31.9,26.0)$ & $(33.0,25.0)$ & 1.49 \\
\hline
\end{tabular}

\section{Conclusions}

This research undertook NDT inspection of BVID in ACS which has aluminum as a facet and with Nomex material as a sandwich core using UGW. The damage regions were successfully analyzed with the help of the A0 wave mode. The Lamb wave interactions and impact damage were visualized and detected. The frequency of excitation at $150 \mathrm{kHz}$ was chosen after studying different frequency ranges. The results from the SLDV appropriately identified the damage location. This yielded a good analysis of the wave pattern and mode changes in the damage region. The Lamb wave propagation and reflection from the damage were identified with SLDV and shown in Figure 2. The SLDV full-field results identified the two different forms of BVID damage and the small hole with the help of UGW. Experimentation performed previously at our laboratory with SLDV identified debonding damage with an area of $0.5 \mathrm{~cm}$ in honeycomb structures with $15 \mathrm{kHz}$, and BVID with a diameter of $0.9 \mathrm{~cm}$ in CFRP structures with $150 \mathrm{kHz}$.

The spectral elemental code was used to analyze similar conditions numerically. The results obtained identified the damage in a similar time period as the experimental case, as shown in Figure 3b. We used a simplified numerical model. The glue layer between the core and skin was not modeled, and no adhesive lever was included between the aluminum skin and the piezoelectric transducer. We identify these factors as the main reasons for the differences between the numerical and experimental signals.

The elliptical signal processing technique works using the methodology of visualization of the wave reflection site. The interaction of the wave with damage creates a higher energy reflected zone. In this method, six different cases were studied, as shown in Table 7. Case 1 corresponds to the result obtained from experimental studies (SLDV) and cases 2-4 are subcases of case 1 . Case 5 corresponds to the result obtained for SEM data and the scanning points placement is similar to case 1 . Case 6 provided the best result in identifying the damage location for SEM data, and case 4 for the SLDV data. Both cases correspond to the same sensor placement. Thus, by using the elliptical method for signal processing, the data obtained from SLDV and SEM was successfully used to locate the damaged region. In summary, experimental and numerical case studies were carried out to understand the wave propagation phenomenon and to locate the damage with sensor network arrangements.

Author Contributions: Conceptualization, K.B., S.S. and P.F.; methodology, K.B. and P.F.; software, K.B. and P.F.; validation, K.B. and P.F.; formal analysis, K.B.; investigation, K.B. and P.F.; resources, P.H.M. and S.S.; data curation, K.B. and P.F.; writing-original draft preparation, K.B. and S.S.; writing - review and editing, K.B., P.F., P.H.M. and S.S.; visualization, K.B., S.S. and P.H.M.; supervision, P.H.M. and S.S.; project administration, P.F., P.H.M. and S.S.; funding acquisition, P.F., S.S. and P.H.M. All authors have read and agreed to the published version of the manuscript.

Funding: This research was funded by National Science Center, Poland under SONATA BIS project with grant agreement no. 2016/22/E/ST8/00068, PRELUDIUM project with the grant no.UMO2018/31/N/ST8/02865, This research was also supported by the Research Foundation-Flanders (FWO) Belgium under grant agreement no. FWO.3E0.2019.0102.01 in the frame of FWO MSCA fellowship.

Institutional Review Board Statement: Not applicable.

Informed Consent Statement: Not applicable. 
Data Availability Statement: The data presented in this study are available on request from the corresponding author. The data are not publicly available due to due to privacy restrictions of the ongoing research.

Acknowledgments: The authors would like to acknowledge the support funding provided by the National Science Centre (NCN), Poland under the SONATA BIS project with the grant agreement no. 2016/22/E/ST8/00068) and the PRELUDIUM project with the grant agreement no. UMO2018/31/N/ST8/02865. Shirsendu Sikdar would like to acknowledge the support by the Research Foundation-Flanders (FWO), Belgium under grant agreement no. FWO.3E0.2019.0102.01. The authors also acknowledge Task-CI for allowing the use of computational resources.

Conflicts of Interest: The authors declare no conflict of interest.

\section{References}

1. Sikdar, S.; Banerjee, S. Structural Health Monitoring of Advanced Composites Using Guided Waves: Online Monitoring of Defects/Discontinuities in Advanced Composite Structures Using Ultrasonic Guided Waves and PZTs; LAP LAMBERT Academic Publishing: Saarbrücken, Germany, 2017.

2. Sikdar, S.; Van Paepegem, W.; Ostachowicz, W.; Kersemans, M. Nonlinear debond response analysis in a smart composite structure using elastic wave propagation. Compos. Part B Eng. 2020, 200, 108304. [CrossRef]

3. Toyama, N.; Yamamoto, T.; Urabe, K.; Tsuda, H. Ultrasonic inspection of adhesively bonded CFRP/aluminum joints using pulsed laser scanning. Jpn. Soc. Compos. Struct. 2017, 43, 201-295. [CrossRef]

4. Diamanti, K.; Hodgkinson, J.M.; Soutis, C. Detection of low-velocity impact damage in composite plates using Lamb waves. Struct. Health Monit. 2004, 3, 33-41. [CrossRef]

5. Hayashi, T.; Kawashima, K. Multiple reflections of Lamb waves at a delamination. Ultrasonic 2002, 40, $193-197$.

6. Park, B.; An, Y.K.; Sohn, H. Visualization of hidden delamination and debonding in composites through noncontact laser ultrasonic scanning. Compos. Sci. Technol. 2014, 100, 10-18. [CrossRef]

7. Song, F.; Huang, G.L.; Hu, G.K. Online Guided Wave-Based Debonding Detection in Honeycomb Sandwich Structures. AIAA J. 2012, 50, 284-293. [CrossRef]

8. Zhao, J.; Li, F.; Cao, X.; Li, H. Wave Propagation in Aluminum Honeycomb Plate and Debonding Detection Using Scanning Laser Vibrometer. Sensors 2018, 18, 1669. [CrossRef] [PubMed]

9. Sikdar, S.; Kudela, P.; Radzienski, M.; Kundu, A. Online detection of barely visible low-speed impact damage in 3D core sandwich composite structure. J. Compos. Struct. 2018, 185, 646-655. [CrossRef]

10. Mustapha, S.; Ye, L. Leaky and non-leaky behaviours of guided waves in CF/EP sandwich structures. Wave Motion 2014, 51, 905-918. [CrossRef]

11. Mustapha, S.; Ye, L.; Dong, X.; Alamdari, M. Evaluation of barely visible indentation damage (BVID) in CF/EP sandwich composites using guided wave signals. Mech. Syst. Signal Process. 2016, 76, 497-517. [CrossRef]

12. Sikdar, S.; Kundu, A.; Jurek, M.; Ostachowicz, W. Nondestructive Analysis of Debonds in a Composite Structure under Variable Temperature Conditions. Sensors 2019, 19, 3454. [CrossRef] [PubMed]

13. Sikdar, S. Multi-level nondestructive analysis of joint-debond effects in sandwich composite structure. Polym. Test. 2019, 80, 106149. [CrossRef]

14. Patera, A.T. A spectral element method for fluid dynamics: Laminar flow in a channel expansion. J. Comput. Phys. 1984, 54, 468-488. [CrossRef]

15. Kudela, P.; Zak, A.; Krawczuk, M.; Ostachowicz, W. Modelling of wave propagation in composite plates using the time domains spectral element method. J. Sound Vib. 2007, 302, 728-745. [CrossRef]

16. Kudela, P.; Ostachowicz, W. 3D time-domain spectral elements for stress waves modelling. J. Phys. Conf. 2009, 181, 1-9. [CrossRef]

17. Ha, S.; Chang, F.K. Optimizing a spectral element for modeling PZT-induced lamb wave propagation in thin plates. Smart Mater. Struct. 2009, 19, 1-12. [CrossRef]

18. Ge, L.; Wang, X.; Wang, F. Accurate modeling of PZT induced lamb wave propagation in structures by using a novel spectral finite element method. Smart Mater. Struct. 2014, 23, 1-15. [CrossRef]

19. Song, F.; G. L. Huang.; K. Hudson. Guided wave propagation in honeycomb sandwich structures using a piezoelectric actuator/sensor system. Smart Mater. Struct. 2009, 18, 1-8. [CrossRef]

20. Ceramtec. Available online: https://www.ceramtec.com/files/ms_piezoceramic-soft-materials_en_de.pdf (accessed on 1 June 2020).

21. Fendzi, C.; Mechbal, N.; Rebillat, M.; Guskov, M.; Coffignal, G. A General Bayesian Framework for Ellipse-based and Hyperbolabased Damage Localisation in Anisotropic Composite Plates. J. Intell. Mater. Syst. Struct. 2015, 27, 350-374. [CrossRef]

22. Soman, R.; Malinowski, P. A real-valued genetic algorithm for optimization of sensor placement for guided waves based structural health monitoring. J. Sens. 2019, 2019, 1-10. [CrossRef] 